\title{
Negative Polarity Item Licensing, Indefinites and Complex Predicates
}

\author{
Myriam Uribe-Etxebarria \\ University of California at Irvine
}

This paper analyzes Negative Polarity Item Licensing in examples where the polarity element is embedded within a preverbal indefinite NP. It is shown that polarity items can be licensed in that configuration even if they are not c-commanded by Neg at SS. The possibility of licensing NPIs within preverbal indefinites correlates with a narrow scope reading of the indefinite and is dependent on the nature of the matrix verb: polarity licensing in that configuration is possible just when the matrix verb is a bleached predicate. It is argued that in the grammatical examples the indefinite NP that contains the polarity item reconstructs at LF; as a consequence of this operation, Neg c-commands the NPI at that level. What triggers reconstruction of the indefinite subject is the need to form a complex predicate out of a light verb and an indefinite NP at LF.

\section{The Problem: Subjects and Negative Polarity Item Licensing}

English displays a very basic asymmetry in the possibility of licensing NPIs in negative sentences: whereas NPIs can be licensed in object position, the presence of a NPI in preverbal subject position yields an ungrammatical result.

(1) a. * Anybody wasn't arrested by the police

b. * Anybody didn't come

(2) The police didn't arrest anybody

Since examples like (3) -where the negative element c-commands SPEC/IP-, are grammatical, most syntactic approaches to the phenomenon have taken the contrast between (1) and (3) as evidence that, in order for the polarity item to be licensed, it must enter into a particular type of structural relation with its licenser. In particular, it has been proposed that the licenser has to c-command the NPI in order for the latter to be licensed. ${ }^{1}$

(3) a. No way anybody is gonna tell me what to do.

b. Not since the Lord himself showed his stuff to Ezekiel to in the valley of dry bones had anyone brought such grace to the reconstruction of animals from disarticulated skeletons. [ from Laka 1990]

In what follows, I will refer to this syntactic requirement as the 'c-command requirement'. ${ }^{2}$ 


\subsection{S-Structure Approach to NPI-licensing}

Assuming that the structure of English clauses is roughly as in (4), with IP dominating NegP, it has been proposed that the reason why the NPIs are not licensed in preverbal subject position in English is because Negation does not c-command Spec/IP at the level of S-structure (see Progovac 1988 and Laka 1990, among others).

\section{(4) $[\mathrm{IP} \quad[\mathrm{NegP} \quad[\mathrm{VP} \quad]]]$}

An analysis along these lines can immediately account for the contrast between (1) and (3). It can also explain the contrast between (1) and (2), or (5a) and (5b) below.

(5) a. I couldn't find [ many doctors who knew anything about acupuncture ]

b. * [ Many doctors who knew anything about acupuncture ] were not available

I will refer to all those approaches that share the assumption that the level at which the c-command requirement has to be met is SS as the 'SS approach to NPIlicensing' (SST).

If the structure of English clauses is as in (4), an immediate prediction of the SST is that Neg will not be able to license any NPI embedded within a preverbal subject. This is so because Negation will not c-command any element within the subject position, the SPEC/IP position, at SS. Keeping this prediction in mind consider (6), from Linebarger 1980.

(6) [ A doctor who knew anything about acupuncture ] was not available

Following the SS approach we would expect (6) to be an illformed example, since Neg does not c-command the NPI embedded within the preverbal indefinite subject at SS. However, contrary to what this approach predicts, (6) is a grammatical example. Thus, although Neg fails to c-command the subject position at SS both in (1) and (6), there is a sharp difference with regard to the grammaticality judgement of these two examples: while (1) is ungrammatical, (6) is a grammatical utterance.

The contrast between (1) and (6) raises a very serious problem for the SS approach to polarity licensing. If what accounts for the ungrammaticality of (2) is that Neg fails to c-command the polarity element at SS, it is not clear why (7) is grammatical; this is so because Neg also fails to c-command the NPI in the good example. The same problem arises if we compare (6) and (7).

(7) *[Many doctors who knew anything about acupuncture] were not available

If, as the SST defends, the SS c-command requirement plays a role in polarity licensing, it is difficult to imagine a way in which this approach can account for both the grammaticality of (6) and its contrast with (1) and (7), at the same time. 


\subsection{LF Approach to NPI-licensing}

Linebarger (1980) observes that the asymmetries in polarity licensing between (6) and (7) are related to the different readings available for the subjects in these examples. Consider (8) and (9), simplified versions of (6) and (7) respectively.

(8) A doctor wasn't available

(9) Many doctors weren't available

The example in (8) is ambiguous: the indefinite subject can take either wide or narrow scope with respect to Neg, as represented in (10). In contrast with (8), (9) is an unambiguous example: it only has the reading represented in (10a). In other words, the only possible interpretation of (9) is that which reflects the surface order between the subject and negation; crucially, Neg cannot take wide scope in this example.

(10) A doctor wasn't available

a. [Ex: $x$ is a doctor] NOT ( $x$ was available)

b. NOT [Ex: $\mathrm{x}$ is a doctor] ( $\mathrm{x}$ was available) [Linebarger 1980: 225]

(11) Many doctors weren't available

a. many $(x)$ [ $x$ a doctor] NOT $x$ are available

b. * NOT many $(x)[x$ a doctor $] \mathrm{x}$ are available

(\# there weren't many doctors available) [Linebarger 1980: 226]

To account for the interpretations of (8) and (9), Linebarger follows Kroch (1974) and assumes that there is a set of reordering rules of quantifiers that takes place in the mapping from SS to LF. These rules permit an optional reordering operation between negation and the preverbal indefinite in examples like (8). As a consequence of reordering Neg can take scope over the indefinite in (8), yielding the reading in (10b), where the indefinite is interpreted as a narrow scope existential. In contrast, this set of rules does not permit reordering between negation and NPs modified by mony from taking place. Consequently, the example in (9) can only have the reading that corresponds to the surface order between many and negation.

Linebarger links the different interpretations displayed by (8) and (9) to the contrast in polarity licensing displayed by their counterparts (6) and (7). In particular, she argues that the NPI can be licensed in (6) because the LF reordering rules of quantifiers permit negation to take scope over the indefinite NP that contains the polarity element at LF, as roughly represented in (12). As a consequence of this reordering operation, Neg c-commands the NPI at LF.

(6) A doctor who knew anything about acupuncture was not available

(12) NOT $\mathrm{E}(\mathrm{x})$ [x: a doctor who knew anything about acupuncture] $\mathrm{x}$ was available

Reordering between Neg and the subject is not permitted in $(7,9)$, however. 
Consequently, (7) only has the construal represented in (13). Within this LF configuration Neg fails to c-command the NPI; it thus follows that the NPI will not be licensed.

(7) * Many doctors who knew anything about acupuncture were not available

(13) Many (x) [x: a doctor who knew anything about acupuncture] $\mathrm{x}$ were

not available

By appealing to LF as the level where scope relations are defined, Linebarger can explain the contrast in licensing possibilities illustrated so far. There are however some questions left unanswered by her account. In particular, it is unclear what the LF reordering operation between Neg and the indefinite is, or what it follows from. Further, her analysis faces some problems to characterize exactly the context where reordering between these two elements takes place. This is so because there are examples with preverbal indefinite subjects, such as (14), where this indefinite cannot take narrower scope than negation.

\section{(14) A doctor didn't know what to do}

Consequently, some additional proviso is needed to prevent LF reordering between the indefinite and Neg from taking place systematically. This poses a problem for Linebarger, since it is hard to predict when the LF reordering rules between the indefinite subject and negation can apply and when they cannot. She acknowledges this difficulty, but no account is given and the issue is left as an open problem. ${ }^{3}$ However, she points out that the contrast in interpretation displayed by examples with indefinite subjects seems to be dependent on the nature of the matrix verb.

\section{The Analysis: Predicates and Negative Polarity Item Licensing}

\subsection{Asymmetries in NPI-licensing}

What is relevant from Linebarger's analysis is that she establishes the connection between the possibility of licensing a NPI within a preverbal subject and the availability of a construal where this subject takes narrower scope than Negation. In what follows I will assume that Linebarger's observation is basically correct. But I will depart from Linebarger and assume that the narrow scope construal of the indefinite subject follows, not from a set of reordering rules, but rather from a reconstruction operation of the indefinite subject to its base-generated position within VP. Since, as Linebarger notes, the scope of the indefinite subject is affected by the nature of the matrix predicate, we still have to find an answer to the question why reconstruction can take place in examples like $(6,8)$ while it cannot apply in other cases.

With this question in mind, let us consider other examples that display an asymmetry in the possibility of licensing a NPI within a preverbal subject. Consider the following examples in (13) to (16), from Linebarger (1980). 
$(15=6)$ [ A doctor who knew anything about acupuncture ] was not available

(16) * [ A doctor who knew anything about acupuncture ] was not intelligent

(17) [ Tickets to any of the afternoon concerts ] were not available

(18) * [ Tickets to any of the afternoon concerts ] were not green

While (15) and (17) are grammatical, (16) and (18) are illformed examples. Note that (13) and (14), on the one hand, and (15) and (16), on the other, are exactly alike except for the matrix verb. This confirms Linebarger's observation that the grammaticality of examples with NPIs in subject position is directly dependent on the nature of the matrix predicate involved. Let us then consider what the difference between the predicates in the grammatical and ungrammatical examples is. An obvious difference comes immediatly to mind: while (to be ) available is an stagelevel (SL) predicate, green and intelligent are individual-level (IL) predicates.

\subsection{The Individual-Level vs. Stage-Level Distinction}

It is well known since Milsark (1974) and Carlson (1977) that these two groups of predicates impose different restrictions on their subjects and, in particular, on their indefinite subjects. Following recent research on the topic (see, among others, Kratzer 1989; Diesing 1990, and Herburger 1993), we could assume that the different properties displayed by indefinite subjects follow from the different positions that these subjects can occupy at LF. While indefinite subjects of $\mathrm{IL}$ predicates can only appear in SPEC/IP at LF, indefinite subjects of SL predicates appear within VP when interpreted with a weak reading.

Let us suppose that this is correct. If so, we can propose that the reason for the contrast in polarity licensing displayed by the pairs in (15-18) is that, although parallel at SS, they have different LF representations. To be more specific, in (15) and (17) the subject appears at LF within its base-generated position in VP, as represented in (19). Note that once reconstructed to its base-generated position, the indefinite subject is c-commanded by Neg at LF. This accounts for the wide scope interpretation of Neg over the indefinite. Moreover, within this configuration, Neg ccommands the NPI at LF; this explains why the NPI can be licensed in these examples.

(15=6) [ A doctor who knew anything about acupuncture ] was not available

(17) [ Tickets to any of the afternoon concerts ] were not available 
(19)

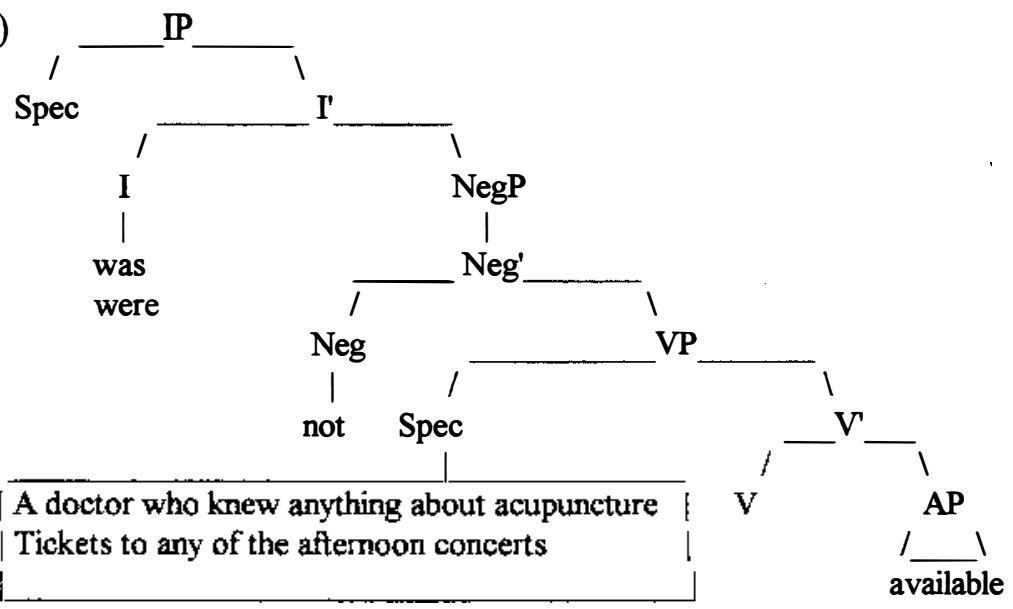

Consider now the ungrammatical (16) and (18). Since the matrix predicate is an II predicate, the subject will have to remain in SPEC/IP at LF, as represented in (20). The LF configuration (20) explains why the indefinite takes wide scope over Neg. It also explains why the NPI cannot be licensed in this example: since the NPI is embedded within the subject in SPEC/IP, it is not c-commanded by Neg at LF.

(16) * [ A doctor who knew anything about acupuncture ] was not intelligent

$(18)^{*}$ [ Tickets to any of the afternoon concerts ] were not green

(20) IP
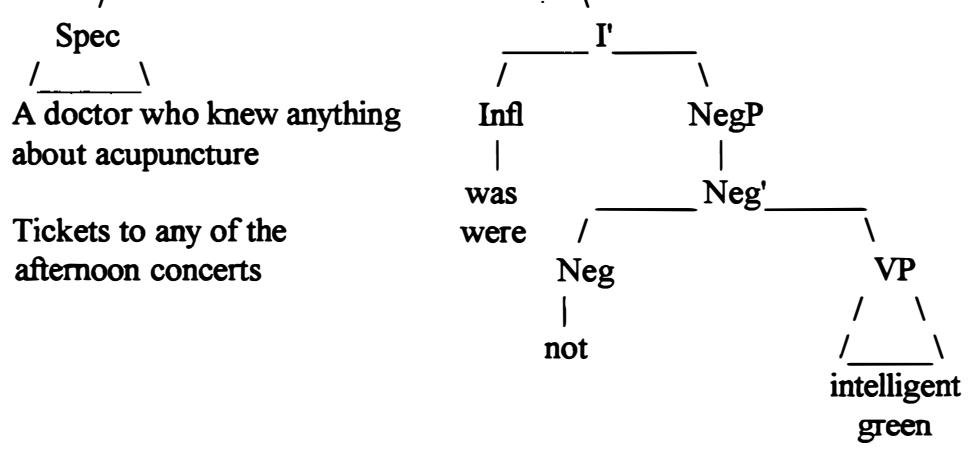

What this analysis predicts is that NPIs embedded within preverbal indefinite NPs will be licensed whenever the matrix verb is a SL predicate. However, as the ungrammaticality of examples like (21) shows, this prediction is not fulfilled.

a. *A fundamentalist yogi that had any interest in philosophy wasn't lying on the floor 
b. * A doctor who knew anything about acupuncture wasn't coming down the stairs

Thus, even if in $(21 a, b)$ the matrix verb is a stage-level predicate, the indefinite subject cannot have a narrow scope reading in these examples. Note, once again, that the lack of a narrow scope interpretation of the subject goes on à par with the impossibility of licensing the NPI.

Consequently, although the generalization holds that in the examples where NPIs are licensed within preverbal indefinites the matrix verb is a stage-level predicate, it is not the case that NPIs within preverbal indefinite subjects are licensed every time a SL predicate is involved. An hypothesis that appeals to the SL vs. IL distinction cannot therefore appropriately characterize when reconstruction of the indefinite NP takes place. ${ }^{4}$ Next, I will propose an alternative analysis, where reconstruction is triggered by the need to create a complex predicate out of a 'bleached verb' and an indefinite NP at LF.

\subsection{NPI-licensing and Complex Predicate Formation}

What is clear from the discussion is that NPIs within preverbal indefinites are only licensed when the indefinite takes narrower scope than Negation; in our terms, when the indefinite reconstructs at LF. As we have just seen, the SL vs. IL distinction is however insufficient to characterize the contexts where reconstruction of the indefinite takes place. Since reconstruction is dependent on the nature of the matrix verb, let us consider other cases where reconstruction of preverbal indefinites is possible.

a. ? A doctor with any knowledge of cancer didn't appear in the hospital yesterday

b. A solution to any of these problems doesn't exist

c. ? A .44 caliber pistol with any accessories wasn't available in the gunshop

d.(?) A messiah who would bring any hope didn't appear to the Jews

There is a relevant feature that these examples share: in all these cases the main predicate is very light in meaning, being practically reduced to the expression of availability, existence, appearance or coming into existence of an object. ${ }^{5}$ The examples in (23-24), due to Barbara Partee (p.c.), further illustrate this generalization.

(23) Examples with any relevance to that issue didn't come up in the discussion

(24) a. An answer to any of these problems hasn't fallen into our laps yet

b. Answers to any of these problems haven't fallen into our laps yet

The meaning of come up in (23a) can be roughly paraphrased as 'appear'; similarly in the case of fall into our laps in (24). Note again that the possibility of licensing the NPI within the preverbal indefinite directly correlates with the narrow scope interpretation of the indefinite subject. 
In a nutshell, in the grammatical examples where a NPI can be licensed within a preverbal indefinite the main predicate is very light in meaning, being practically reduced to the expression of availability, existence, appearance or coming into existence of an object. Assuming that the above generalization is correct, I propose the following hypothesis:

(25) NPIs within preverbal indefinite subjects are only licensed when the matrix predicate is a light, 'bleached' predicate.

The term 'bleached predicate' is borrowed from Szabolcsi (1986). Szabolcsi observes that Hungarian verbs conform to the generalization in (26): ${ }^{6}$

(26) In Hungarian, verbs which express existence, or change in the state of existence or availability of the denotation of the designated Noun Phrase show Definiteness Effects (DE) when no aspectual prefix is attached to them.

Consider the examples in (27), which illustrate the generalization (26). (27a) and (27b) -where the verb has no aspectual affixes attached to it and the object is an indefinite NP-, are grammatical examples. Consider now (26c). As in the other examples in (26), the verb is also prefixless; but now the object is either a definite NP or an NP headed by a strong determiner, and the examples are ungrammatical. As (28) shows, when the aspectual prefix meg is added to the verb in (27c), the DE disappears and the example becomes grammatical.

$$
\oslash+V \text { (Definiteness Effects) }
$$

a. Mari $\oslash+$ talált tollat / (némi) tejet

Mary $\odot+$ found pen-acc / (some) milk-acc

Mary found a pen / sm milk'

b. Mari nem $\theta+$ talált tollat / (némi) tejet

Mary nem $\varnothing+$ found pen-acc / (some) milk-acc

Mary not found (any) pen / (any) milk'

c. * Mari $\theta+$ talált(a) a tollat / minden tollat $[D E]$

Mary $\theta+$ found the pen-acc/ every pen-acc

Mary found the pen / every pen'

\section{(28) Aspectual Prefix + V (No Definiteness Effects)}

Mari megtalált(a) két tollat / a tollat

Mary pfx-found two pen-acc/ the pen-acc

'Mary found two pens / the pen'. 
Szabolsci argues that Hungarian verbs that conform to the pattern in (26), like van 'to be, to have', akad 'to happen to exist', érkezik 'to arrive', kerül 'to become available', etc., have their meaning reduced to the assertion of (a change in the state of) existence. She calls them 'bleached verbs'. She assumes that every predicate of natural language must have some content. Since the meaning of bleached verbs amounts to a logical predicate of existence plus, plausibly, a change operator, they must be 'substantiated' with some lexical content. She further proposes that the indefinite NP, which she assumes is in a sisterhood relation with the verb at the V'level, serves as the 'lexical integer' which substantiates the verb with the necessary lexical content, as roughly represented in (29).

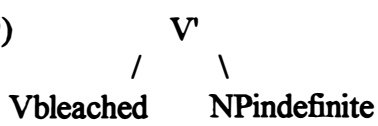

It is the fact that this indefinite NP has to appear under the V'-level in a strict sisterhood relation with the verb that yields the definiteness effects displayed by these verbs.

Keeping this in mind, let us now come back to our problem. Recall that in the grammatical examples where NPIs are licensed within preverbal indefinite NPs, the predicate is very 'light' in meaning, being practically reduced to the expression of availability, existence, appearance or coming into existence of an object. On the basis of what we have seen so far, it is reasonable to propose that the 'light' predicates of the grammatical examples where NPIs are licensed within preverbal subjects are the English counterparts of the Hungarian bleached verbs.

Szabolcsi argues that bleached verbs have difficulties in assigning argument $\boldsymbol{\theta}$-roles, and need to get substantiated with some lexical content. Let us assume that in order to be licensed at LF, NPs need to be assigned a $\Theta$-role and predicates need to have some lexical content. The LF operation described by Szabolcsi in the sense that the indefinite substantiates the bleached verb can be understood as a complex predicate formation that allows both the indefinite NP and the bleached verb to be licensed. Since the indefinite cannot get a $\Theta$-role from the bleached verb, it cannot be licensed as an argument. By forming a complex unit with the bleached verb, it can be licensed in a different way, as part of a predicate. ${ }^{7}$ By forming a unit with the indefinite, on the other hand, the bleached prodicate is substantiated with lexical content. This complex predicate formation operation that the bleached predicate and the indefinite undergo can be understood as a way to comply with the principle of Full Interpretation.

In the examples we are considering, the indefinite which is to form a complex predicate with the bleached verb surfaces in SPEC/IP: it is the preverbal indefinite NP that contains the polarity item. At SS, the indefinite is not a sister to the bleached predicate. I propose that in the grammatical examples under study with the structure in (30), the preverbal indefinite has to reconstruct at LF in order to be in a strict sisterhood relation with the bleached predicate and form a complex predicate with it. The LF of the grammatical examples where NPIs are licensed within preverbal 
subjects is as in (31).

(30) $\left[{ }_{N P}[\ldots\right.$ NPI ... ] ] Aux Neg V

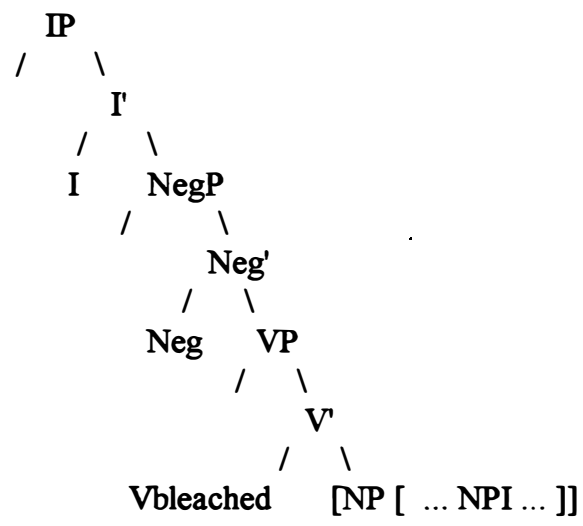

If the LF representation in (31) is correct, we can now understand why the NPIs can be licensed when the matrix predicate is a bleached verb: within this LF configuration Neg c-commands the NPI at LF.

Summanizing, the grammatical cases where a NPI can be licensed within a preverbal indefinite NP involve bleached predicates. At LF, the indefinite subject reconstructs in order to form a complex predicate with the bleached verb. As a consequence of this reconstruction operation, Neg c-commands the NPI at LF. The LF representation of the ungrammatical cases is different. In particular, the indefinite subject remains in SPEC/IP at LF; consequently, Neg does not c-command the polarity element at LF.

The question finally arises how to rule out ungrammatical examples like (32), where the matrix verb is a bleached predicate.

(32) * Anybody didn't appear

I address this issue next.

\subsection{Any-Subjects}

As mentioned in section 1, the ungrammaticality of examples like (1) has been accounted for by the SST as resulting from the failure to meet the c-command requirement at SS.

(1) a. * Anybody wasn't arrested by the police

b. * Anybody didn't come

As has been shown, this analysis cannot be correct, since NPIs can be licensed in 
examples where Neg does not c-command the NPI at SS. We have seen that the failure to meet the c-command requirement at SS is not relevant to explain the polarity item licensing facts; it is just the LF structural relation between the polarity licenser and the NPI that matters.

I have argued that in the grammatical cases where NPIs within preverbal subjects are licensed the matrix verb is a bleached predicate. I have proposed that what accounts for the grammaticality of these examples is that the indefinite subject reconstructs at LF. After reconstruction takes place, Neg c-commands the subject at LF. The question then arises why polarity subjects are not licensed in examples where the matrix verb is a bleached predicate, such as (32). In other words, why is it that polarity subjects cannot be licensed through a reconstruction operation of the sort we have appealed to in the previous subsection.

(32) * Anybody wasn't available

There are at least a couple of possibilities to explore:

Suppose, first, that any-phrases cannot reconstruct at LF. If they cannot reconstruct, they will not be c-commanded by Neg at LF. In this respect, any-phrases would be similar to many-phrases. As discussed in section 1, negative sentences with subjects modified by many are (generally) not ambiguous, and the subject shows a very strong preference to take scope over negation. Some illustrative examples are repeated below.

(10) A doctor wasn't available

a. [Ex: $x$ is a doctor] NOT ( $x$ was available)

b. NOT [Ex: $x$ is a doctor] ( $x$ was available) [Linebarger 1980: 225]

(11) Many doctors weren't available

a. many $(x)$ [ $x$ a doctor] NOT $x$ are available

b. * NOT many $(x)[x$ a doctor $] x$ are available

(\# there weren't many doctors available) [Linebarger 1980: 226]

Although the reasons why negative sentences involving many-subjects are not ambiguous are not totally clear, the lack of ambiguity of this type of example can be taken as an indication that NPs modified by many cannot reconstruct in negative sentences. The ungrammaticality of examples like (32) could be then explained in similar terms: (32) is ungrammatical because inherent properties of polarity phrases prevent them from reconstructing. The ungrammaticality of (30) would then have to be explained together with the lack of ambiguity of (11) and the ungrammaticality of (7). ${ }^{8}$

(7) * Many doctors who knew anything about acupuncture were not available

There is an altemative possibility, however. Suppose that nothing prevents reconstruction of any-phrases in examples involving bleached predicates. Let us then 
assume for the sake of the argumentation that reconstruction of the polarity-phrase can take place in those constructions. The resulting LF structure would be roughly as in (33).

(32) * Anybody didn't appear

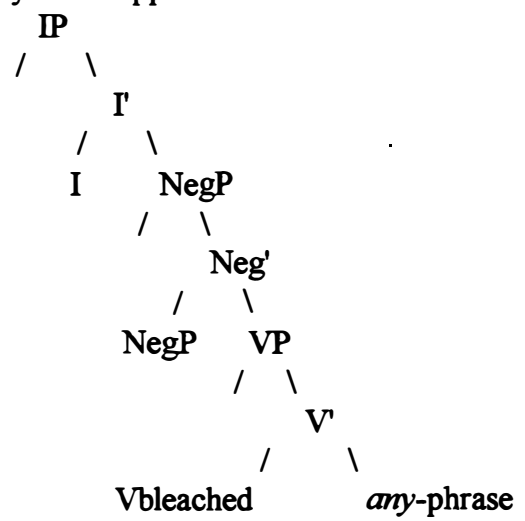

If reconstruction is possible, the question then is what is wrong with the resulting configuration in (33). I would like to propose that if reconstruction is possible, as we are entertaining here, the ungrammaticality of cases like (33) follows because anyphrases cannot form complex predicates with bleached verbs. The question arises why this should be so. I will like to suggest that what prevents polarity-phrases from forming complex predicates with bleached verbs is that polarity items are dominated by functional categories (see Cheng 1991: 85). If this is correct, we now have an explanation why any-phrases cannot form complex predicates with bleached verbs. The reason is that by substantiating the bleached verb, the indefinite forms a complex predicate with it. Complex predicate formation is a lexical operation. Only lexical categories can take part in lexical formation operations; no complex lexical item can be created out of lexical and functional categories. Since the polarity item is dominated by a functional category, no complex predicate formation can take place in (33). The consequence of this is that neither the bleached verb nor the polarityphrase will be licensed in (33). The bleached verb will not be licensed because it will not have any lexical content. The polarity-phrase, in turn, cannot be licensed as part of the predicate because it dominated by a functional category; further, it cannot be licensed as an argument either, since the bleached verb cannot assign any $\Theta$-role to it. As a result, the structure is ruled out.

\section{Some Extensions: Complex Predicate Formation and Tense}

To finish, I would like to point out that there are some cases where reconstruction of the indefinite is not possible even if the matrix verb is a bleached predicate. In particular, there are cases where independent licensing conditions imposed on the indefinite NP prevent reconstruction of the preverbal subject from 
taking place. In those cases, Neg does not c-command the NPI at LF, and the NPI cannot be licensed.

Consider the examples in (34); the preverbal subject is an indefinite NP and the matrix predicate is a bleached verb. Following the analysis we have pursued in the previous section we would expect these two examples to allow a narrow scope reading of the indefinite subject. However, while the indefinite subject can take either a narrow or a wide scope interpretation in (34a), most speakers can only get a wide scope interpretation of the subject in (34b). The readings of these examples are roughly given in (35).

(34) a. [A performer [ who is wearing funny clothes ]] isn't available

b. [ A performer [ who is wearing funny clothes ]] wasn't available

(35) a. Neg $E(x) ; E(x) \quad N e g$

b. *Neg $E(x) ; E(x)$ Neg

In Uribe-Etxebarria (1994) I propose that the reason why the subject can only have a wide scope interpretation in (34b) is that, if the indefinite reconstructs, the embedded relative clause cannot satisfy its morphological tense licensing requirements in its base-generated position (see also Stowell 1993). The tense licensing conditions of the relative clause in (34b) force the indefinite to remain in SPEC/IP at LF; consequently, reconstruction of the indefinite subject is not possible in (34b). The prediction of our analysis is that NPIs will not be licensed within the indefinite subject in (34b). In contrast, we expect that NPIs within the preverbal subject will be licensed in (34a). As the contrast between (35a) and (35b) shows, this prediction is fulfilled.

(35)a. [A performer [ who is wearing any funny clothes ]] isn't available

b. * [ A performer [ who is wearing any funny clothes ]] wasn't available

Once again, the impossibility of reconstructing to the VP internal position correlates with the impossibility of licensing a NPI within the preverbal subject. While at LF Neg c-commands and licenses the NPI in (35a), it cannot c-command the NPI embedded within the subject sitting in SPEC/IP in (35b). Consequently, licensing cannot take place in this example.

If the approach defended in this paper is correct, it provides further support to the hypothesis that Negative Polarity Item takes place at LF, and not at SS. This is consistent with recent proposals that there are no SS conditions and that all conditions on representations must apply at the interface levels PF and LF.

\section{Endnotes}

* I am indebted to Jun Abe, Filippo Beghelli, Hamida Demirdache, Ken Hale, Elena Herburger, Irene Heim, Hiroto Hoshi, Utpal Lahin, Howard Lasnik, Alec 
Marantz, Renate Musan, Javier Ormazabal, Barbara Partee, David Pesetsky, Colin Phillips, Mamoru Saito, Tim Stowell and Juan Uriagereka for helpful comments and suggestions. This research has been supported by a scholarship from the Department of Education, Universities and Research of the Basque Government.

1. See Klima (1964), Jackendoff (1972) and Lasnik (1972) for an analysis of the structural relation to be met by licenser and licensee in terms of 'in construction with', precede and command' and 'command', respectively.

2. It should be kept in mind that meeting the c-command requirement does not immediatly guarantee that the NPI will be licensed, since there might be additional conditions (locality requirements, etc.) that must be also met. In other words, the ccommand requirement is a necessary (but not always sufficient) condition for licensing to take place.

3. Note that we are dealing with two different types of problems regarding the contrast in construal possibilities of displayed by certain subjects in affimative and negative clauses:

One problem is that of the many-subjects: although it is not clear what it follows from, affirmative and negative sentences behave differently with respect to the construal possibilities of this type of subjects. In particular, in negative sentences preverbal mamy-NPs show a very strong preference for a reading where they take scope over negation.

A different problem is that of indefinite NPs of the type $a$-NP. Contrary to the former, $a$-NP indefinites do not follow a single pattern, but rather show a great degree of variation with respect to the interpretation possibilities of the subject in negative clauses. It is this degree of variation that we try to partially account for in this section.

4. What follows from the discussion is that affrmative and negative sentences display a very different behavior with respect to the scopal properties of indefinite subjects. While indefinite subjects can easily get a narrow scope interpretation in affirmative sentences involving SL predicates, a narrow scope interpretation of the subject is usually very hard -if not impossible- in negative sentences. This can be easily shown by the change in interpretation that examples used to illustrate the ambiguity of clauses involving SL predicates suffer when transformed into negative sentences: most of them become unambiguous, with a strong interpretation of the indefinite subject.

This raises the question of what property of negative sentences this behavior can follow from. One possibility to explore is that negation changes the type of predicate. In particular, it might be argued that Neg changes a stage-level predicate into a stative or non-eventive predicate; this might in tum affect the way in which the indefinite can be interpreted. For related discussion, see Partee $(1973,1984)$.

5. I am indebted to Barbara Partee for this observation.

6. Thanks to Irene Heim for bringing these facts to my attention. 
7. See de Hoop (1992) for an analysis where indefinites with weak Case are interpreted as part of the predicate.

8. For related discussion, see Beghelli and Stowell (1995).

\section{References}

Abusch, D. (1988): 'Sequence of Tense, Intensionality and Scope', Proceedings of WCCFL VIII.

Beghelli, F. \& T. Stowell (1995): 'Distributivity', ms. UCLA.

Carlson, G. (1977): Reference to Kinds in English, Ph. D. Dissertation UMASS, Amherst.

Chomsky, N. (1992): 'A Minimalist Approach to Linguistic Theory', ms. MIT.

Diesing, M. (1992): Indefinites, MIT Press.

Enç, M. (1987): 'Anchoring Conditions for Tense', LI 18.

Herburger, E. (1993): 'Focus and the LF of Quantification', Proceedings of SALT III.

Hornstein, N (1990): As Time Goes By, MIT Press.

Jackendoff, R. (1972): Semantic Representation in Generative Grammar, MIT Press.

Klima, E. S. (1964): 'Negation in English' in J. Fodor and K. Katz (eds.): The Structure of Language, Englewoods Cliff, N. J.: Prentice-Hall.

Kratzer, A (1989): 'Stage-Level and Individual-Level Predicates', Papers on Quantification. UMASS, Amherst.

Ladusaw, W. (1979): Polarity Sensitivity as Inherent Scope Relations, Ph. D. Dissertation, U. of Texas.

(1977): 'Some Problems with Tense in PTQ', Texas Linguistic

Forum 6, 89-102. Austin.

Laka, I. (1990): Negation in Syntax, Ph. D. Dissertation, MIT.

Lasnik, H. (1972): Analyses of Negation in English, Ph. D. Dissertation, MIT.

Linebarger, M. (1980): The Grammar of Negative Polarity, Ph.D. Dissertation, MIT.

Milsark, G. (1974): Existential Sentences in English, Ph. D. Dissertation, MIT.

Ogihara, T. (1990), Temporal Reference in English and Japanese, Ph.D. Dissertation, U. of Texas.

Partee, B. (1988): 'Many Quantifiers', Proceedings of ESCOL 1988.

(1984): Nominal and Temporal Anaphora', Linguistics and Philosophy 7.

(1973): 'Some Structural Analogies between Tenses and Pronouns in English', The Journal of Philosophy 70.

Progovac, L. (1988): A Binding Approach to Polarity Sensitivity, Ph. D. Dissertation, University of Southern Califomia.

Stowell, T. (1993): 'Syntax of Tense', ms. UCLA.

Szabolsci, A. (1986): 'Indefinites in Complex Predicates', Theoretical Linguistic Research 2.

Uribe-Etxebarria, M. (1994): Interface Licensing Conditions on Negative Polarity 
Licensing: A Theoryof Polarity and Tense Interactions. Ph. D. Dissertation, UCONN.

Zagona, K. (1990): 'Times as Temporal Argument Structure', Time in Language Conference, MIT.

(1989): 'On the Non-Isomorphism of Morphological Tense and Temporal Interpretation', Proceedings of the LSRL XIX. 